\title{
Synthesis and antibacterial studies of some new amides of 5- sulphosalicylic acid
}

\author{
Anjali Mishra ${ }^{1}$, Manoj Kumar ${ }^{3}$, Ashok Mishra ${ }^{1}$, Arvind Kumar ${ }^{2}$, Ravi Kant ${ }^{4}$, Thakur R.S. ${ }^{1 *}$ \\ ${ }^{1}$ Research Laboratory, Department of Chemistry, D.B.S.P.G. College, Kanpur \\ ${ }^{2}$ Department of Chemistry, K.K. College, Etawah \\ ${ }^{3}$ Department of Applied Chemistry, Vidya Bhawan Engineering College, Kanpur \\ ${ }^{4}$ Department of Medicinal Chemistry, Mahatma Gandhi Institute of Pharmacy, Lucknow
}

\begin{abstract}
Some new amides of 5-Sulphosalicylic acid were synthesized by the reaction of suitable amines with 5-sulphosalicylic acid in 2:1 ratio. The compounds are novel and first time screened for their biological evaluation along with general characterization with the help of elemental analysis, IR spectral analysis. These compounds showed higher to moderate biological activity against different pathogenic microbial strains.
\end{abstract}

Keywords: 5-Sulphosalicylic acid, amines, antibacterial activity.

\section{Introduction}

The nitrogen and sulfur containing compounds plays important role in medicine for the treatment of various kinds of bacterial and fungal diseases caused by different pathogenic bacterial and fungal strains [1-4]. The sulfur containing compounds also used essentially for the treatment of different kinds of tumors along with gastric ulcer caused by Helicobacter pylori [5-7]. Presence of nitrogen and sulphur generally enhances the efficacy of the compound against the infection [8].Recently our group reported the synthesis and bio-medicinal importance of some novel amides of 5-sulphosalicylic acid [9].In continuation of our research work on amides of sulphosalicylic acid, the present communication reveals the synthesis and biomedicinal importance of some novel amides of 5-sulphosalicylic acid.

\section{Results and Discussion}

The amides of 5-sulphosalicylic acid were synthesized by the general procedure as shown below.

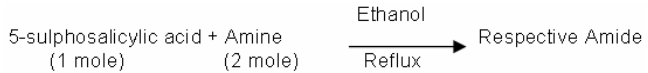

All the compounds were crystalline solids and quite stable at room temperature with good yield $(70-75 \%)$. The compounds were soluble in polar solvents. They have sharp melting points. The compounds were also characterized on the basis of elemental analysis and IR spectra.

\section{I.R. Spectra}

The solid state FTIR spectra of all these compounds were recorded in the spectra range of $4000-400 \mathrm{~cm}^{-1}$ and significant frequencies were observed in this region. The IR spectra of the entire compound shows absorption band due to phenyl group of 5sulphosalicylic acid. The absorption frequencies of carbonyl group in the amide derivative have been assigned. Clearly, confirming the proximal geometrical arrangement.

\section{Antibacterial activity}

The amides of 5-sulphosalicylic acid were tested for antibacterial activity against three pathogenic bacterial strains viz. Pseudomonas aeruginosa, Staphylococcus aureus and Klebsiella pneumoniae, using $10 \mu \mathrm{g} / \mathrm{ml}$ concentration of the compound. The compounds show positive antibacterial activity. It was found that the positive activity of these entire compounds was due to presence of different kinds of amino group. The activity of compound 1 found higher against Pseudomonas aeruginosa while compound 3 show higher efficacy against Staphylococcus aureus and Klebsiella pneumoniae respectively. The efficacy of compound 6 against Klebsiella pneumoniae was also found higher. The biological activity of these entire compounds generally occurs due to presence of nitrogen and sulphur contents in the molecule, presence of hydrogen bonding in 5sulphosalcylic acid, presence of polar $\mathrm{OH}$ groups which increases the water solubility. These compounds generally reacted with some groups of bacterial cell wall and damage it is such a manner that the aromatic ring gets entered inside the cell wall followed by death of bacterial cell.

\section{EXPERIMENTAL}

The synthesis of amides of 5-sulphosalicyclic acid was carried out by following method.

5-sulphosalicylic acid + Amines $\underset{\text { Fthanol }}{\stackrel{\text { Refluxing }}{\longrightarrow} \text { Amides of 5-sulpho salicylic acid }}$ Amines taken: $p$-methoxyaniline,
aminopyridine, aniline, $\alpha$-naphthylamine, p-chloroaniline and hydrazine).

The amines were purified by crystallization before use. Molecular weights of the compounds were determined cryoscopically. The infra red spectra (FTIR) of new compounds were recorded in a Perkin-Elmer spectrophotometer in $4000-200 \mathrm{~cm}^{-1}$ range. The further characterization of these compounds is in progress. The method of preparation of some representative compounds is given below. 
Reaction of 5-sulphosalicylic acid with pmethoxy aniline (1)

An ethanolic solution of 5-suphosalicylic acid (2.5 gm; 1 mole) and $p$-methoxy aniline (2.46 $\mathrm{gm} ; 2 \mathrm{~m} \mathrm{~mol}$ ) was refluxed together at room temperature for 6-7 hrs, followed by their evaporation and concentration in vacuum gives a crystalline solid which was recrystalized in ethanol to give respective amide of 5sulphosalicylic acid.

Reaction of 5-sulphosalicylic acid with $\alpha$ naphthylamine (4)

An ethanolic solution of 5-sulphosalicylic acid ( $2.5 \mathrm{gm} ; 1 \mathrm{~m}$ mole) and salicylic acid

a-naphthylamine (2.86 gm; $2 \mathrm{~m}$ mole) was refluxed together at room temperature for 6-7 hrs, followed by their evaporation and concentration in vacuum afforded a crystalline solid mass which was further recrystalized in ethanol to gives respective amides.

Reaction of 5-sulphosalicylic acid with hydrazine (6)

An ethanolic solution of 5-sulphosalicylic acid ( $2.5 \mathrm{gm} ; 1 \mathrm{~m}$ mole) and hydrazine $(0.64 \mathrm{gm} ; 2$ $\mathrm{m}$ mole) was refluxed together at room temperature for $6 \mathrm{hrs}$, followed by evaporation and concentration in vacuum afforded a crystalline solid which was further recrystalized in ethanol to give respective amides.

\section{Antibacterial Activity}

The antibacterial activity of these compound was carried out by disc diffusion method [10], using Gentamycin as standard. In this technique the filter paper (Whatman No.1) sterile disc of $5 \mathrm{~mm}$ diameter, impregnated with the test compounds $(10 \mu \mathrm{g} / \mathrm{ml}$ of ethanol) along with standard were placed on the nutrient agar plate at $37^{\circ} \mathrm{C}$ for $24 \mathrm{hrs}$ in BOD incubator. The inhibition around dried impregnated disc was measured after $24 \mathrm{hrs}$. The bacterial activity was classifieds as highly active $($ dia $=>15 \mathrm{~mm})$, moderate active (dia = $10-15 \mathrm{~mm}$ ) and partially active (dia $=5-10$ $\mathrm{mm})$.

\section{Conclusion}

The newly synthesized amides of 5sulphosalicyclic acid have great potential as antibacterial agents, and therefore can be explore further for the development of new drugs for treatment of bacterial diseases.

\section{Acknowledgement}

The authors are highly thankful to the Director RSIC, CDRI Lucknow for spectral and elemental analysis. The authors are also thankful to Principal, D.B.S. P.G. College, Kanpur for providing necessary laboratory facility.

\section{References}

[1] Bishayee A., Karmaker R., Mandal A., Kundu S.N. and Chaterjee M. (1997) Eur. J. Cancer. Prev. 6, 58-70.

[2] Chakraborty A. and Chaterjee M. (1994) Neoplasma, 41, 291-296.

[3] Cruz T.F., Morgon A. and Min W. (1995) Mol. Biochem, 153, 161-166.

[4] Chitamber C.R. and Wereley J.P. (1997) J. Biol. Chem., 272, 12151-12157.

[5] Collery P., Millart H., Pluot M. and Anghileri L.J. (1986) Anticancer. Res., 6, 10851088 ,

[6] Tajmir-Riahi H.A., Naovi M. and Ahmad R. (1990) Toxicol. Appl. Pharmacol; 106, 462-468.

[7] Barone G., Ramusino M.C,. Barbieri R. and Manna G.L. (1999) J. Mol. Struct, 469, 143.

[8] Kayser F., Biesemans M., Gielen M. and Willem R. (1994) Magn. Reson. Chem., 32, 358.

[9] Mishra Anjali, Singh R.K., Singh S., Mishra A., Kumar M., Ravi Kant and Thakur R.S. (2009) Int. J. of Pharmaceutical Analysis, 1(2), 1-3.

[10] Verma R.S. and Imam S.A. (1973) Ind. J. Microbial, 
Anjali Mishra, Manoj Kumar, Ashok Mishra, Arvind Kumar, Ravi Kant, Thakur RS

Table 1- Analytical data of complexes (1:2) of 5-Sulphosalicylic acid.

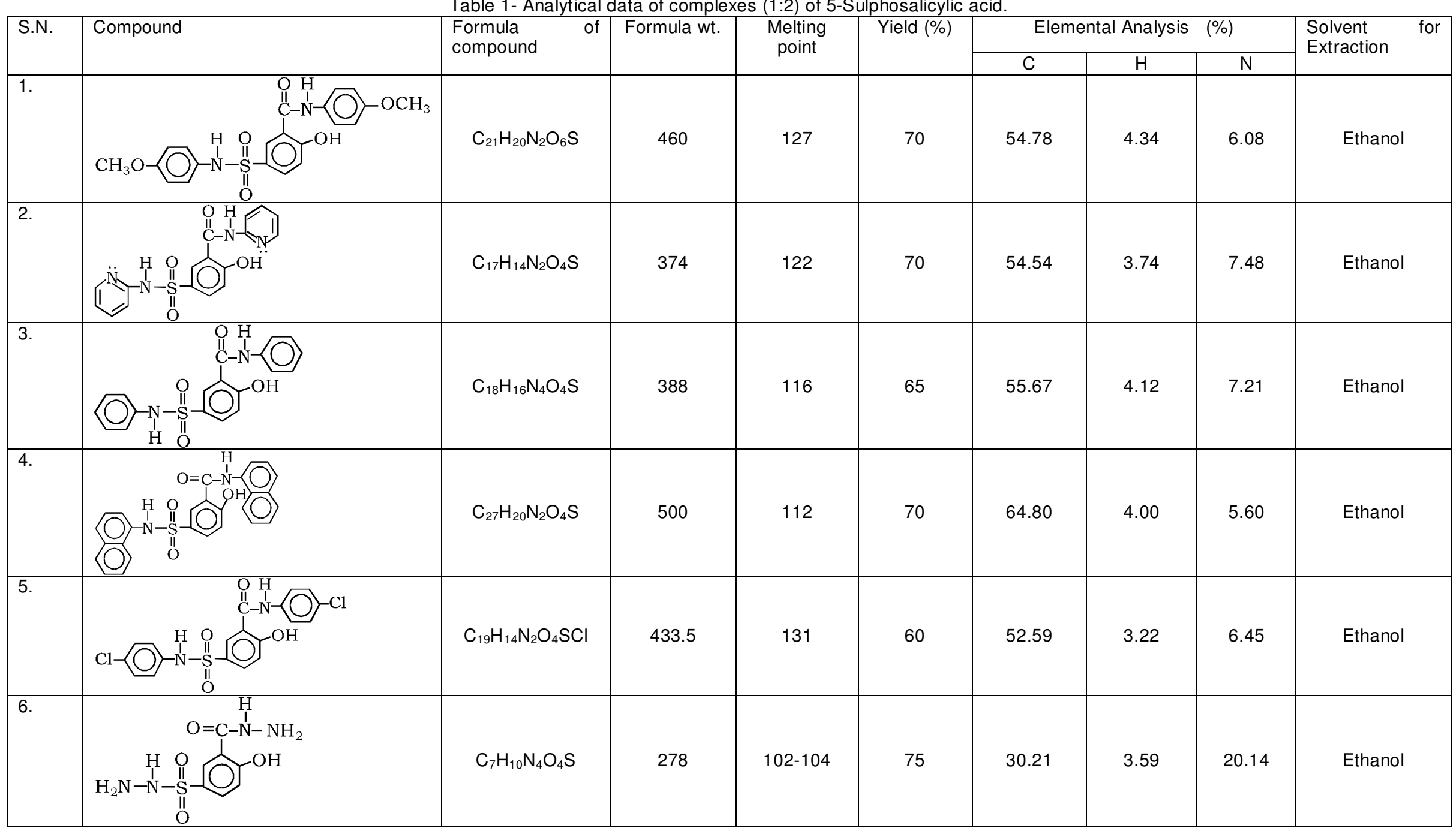


Synthesis and antibacterial studies of some new amides of 5-sulphosalicylic acid

Table 2- Antibacterial Activity.
\begin{tabular}{|l|l|c|c|c|c|}
\hline S.N. & Compound & Control & P. aeruginosa & S. aureus & K. pneumoniae \\
\hline 1. & $\mathrm{C}_{21} \mathrm{H}_{20} \mathrm{~N}_{2} \mathrm{O}_{6} \mathrm{~S}$ & - & +++ & ++ & + \\
\hline 2. & $\mathrm{C}_{17} \mathrm{H}_{14} \mathrm{~N}_{2} \mathrm{O}_{4} \mathrm{~S}$ & - & ++ & ++ & ++ \\
\hline 3. & $\mathrm{C}_{18} \mathrm{H}_{16} \mathrm{~N}_{4} \mathrm{O}_{4} \mathrm{~S}$ & - & ++ & +++ & +++ \\
\hline 4. & $\mathrm{C}_{27} \mathrm{H}_{20} \mathrm{~N}_{2} \mathrm{O}_{4} \mathrm{~S}$ & - & ++ & ++ & ++ \\
\hline 5. & $\mathrm{C}_{19} \mathrm{H}_{14} \mathrm{~N}_{2} \mathrm{O}_{4} \mathrm{SCl}$ & - & ++ & ++ & ++ \\
\hline 6. & $\mathrm{C}_{7} \mathrm{H}_{10} \mathrm{~N}_{4} \mathrm{O}_{4} \mathrm{~S}$ & - & ++ & ++ & +++ \\
\hline \\
$++=(10-15 \mathrm{~mm}$ dia) \\
$+++=(>15 \mathrm{~mm}$ dia) \\
$(-)=$ Control
\end{tabular}

